\title{
A SIMPLE EQUATION FOR ICE SHEET THICKNESS AND ICE FORMATION/BREAKUP PREDICTION
}

\author{
Yasuhiro YOSHIKAWA ${ }^{1}$, Yasuharu WATANABE² and Akashi ITOH $^{3,4}$ \\ ${ }^{1}$ Member of JSCE, Assistant Professor, Dept. of Civil and Environmental Eng., Kitami Institute of Technology \\ (Koen-cho 165, Kitami, Hokkaido 090-8507, Japan) \\ E-mail: yoshi@mail.kitami-it.ac.jp \\ ${ }^{2}$ Member of JSCE, Professor, Dept. of Civil and Environmental Eng., Kitami Institute of Technology \\ (Koen-cho 165, Kitami, Hokkaido 090-8507, Japan) \\ E-mail: y-watanb@mail.kitami-it.ac.jp \\ ${ }^{3}$ Member of JSCE, Team Leader, River Eng. Research Team, Civil Eng. Research Inst. for Cold Region \\ (Hiragishi 1-3-1-34, Toyohira-ku, Sapporo 062-8602, Japan) \\ E-mail: ito-a2tu@ceri.go.jp \\ ${ }^{4}$ Present address: Member of JSCE, Rumoi Dev. Dept. Manager, Hokkaido Regional Dev. Bureau \\ (Kotobuki-cho 1-68, Rumoi, Hokkaido 077-8501, Japan) \\ E-mail: ito-a2tu@hkd.mlit.go.jp
}

\begin{abstract}
In this study, simple equations for calculating ice sheet thickness were developed on the basis of an ice sheet thickness simulation model that used heat flux. In an array of equations, the coefficients $\alpha$ and $\beta$ represented the effects of both snow cover and frazil ice and the effects of river ice melting, respectively. The air temperature, the water temperature, and the effective water depth were represented by independent variables. A method for calculating the ice sheet thickness on the basis of data on the air temperature alone was established. In this method, water temperatures were calculated by using air temperatures and simple equations, and a constant value was given to the effective water depth. The ice sheet thickness in a river was successfully determined by using a non-contact measuring technique. The values measured by this technique were reproduced by the values calculated by simple equations that used the air temperature as the sole input value. The simple equation using the sole input value of air temperature for calculating the ice sheet thickness was also used for retrospectively predicting the day when river water began to freeze and the day when river ice began to break for the past nine years on an actual river. The mean absolute errors in the prediction of the day of ice formation and the day of ice breakup on the basis of calculated values were 6 days and 2 days, respectively, in comparison with the predictions based on the measured values. This suggests that the simple equation is useful for accurate prediction of the days of ice formation and ice breakup.
\end{abstract}

Key Words : frozen rivers, ice sheet thickness, calculation, ice formation, ice breakup, Hokkaido, Japan

\section{INTRODUCTION}

Decreases in the air temperature as well as in the flow velocity in winter cause ice formation in rivers in cold regions. In early spring, when the temperature and the flow velocity increase, the ice in rivers begins to melt, break, and flow downstream ${ }^{1}$. River ice consists of hard ice sheets on the water surface, soft frazil ice in flowing water, and snow accumulated on the ice sheets.

Techniques for predicting the ice sheet thickness as well as the days when the ice begins to form and break up are required to ensure the safety and advance planning of river works and flow rate observations when rivers are frozen. A method ${ }^{2}$ ) that was recently developed for estimating flow discharge in frozen rivers on the basis of the area of flowing water (value A) and the width of the water surface (value B) plus "value C" is not applicable to rivers where field observation is difficult, because this method requires measurement of the river area covered with ice. To develop a more versatile method, a technique for estimating the area of the ice-covered river is necessary. 
When the ice in a river begins to break up, ice floes flowing downstream block the river channel at places where the channel's plane shape varies due to narrowing or meandering and where there are bridge piers or structures crossing the river. This blockage results in ice jams that cause a sudden rise in the water level3),4). Techniques for predicting the time of ice jam formation are necessary for effective management of rivers. Because ice begins to break up immediately before ice jams begin to occur, the precise prediction of ice breakup is useful.

Specifically, if the changes in the ice sheet thickness are simulated for a period from the initiation of ice formation to complete thaw, it is possible to predict both the early ice formation period and the ice breakup period, the time of ice jam formation, and the flow discharge in a frozen river. Accurate prediction of these will be helpful for advance planning of river works as well as for safe flow rate observation. Management of frozen rivers will also benefit from the knowledge that becomes available through accurate prediction. Furthermore, techniques for accurate prediction will make it possible to assess how the ice sheet thickness is affected by changes in the hydraulic quantities of river water that result from an increase in snowmelt or changes in weather conditions (e.g., extremely mild or cold winters). Consequently, it will be possible to examine the effects of climate change on frozen rivers.

In this study, a model for simulating the ice sheet thickness by means of heat flux was used to develop equations for the ice sheet thickness. In the equations, the coefficient $\alpha$ represented the effects of snow cover and frazil ice, and the coefficient $\beta$ represented the effects of river ice melting. The air temperature, the water temperature, and the effective water depth are independent variables. Additionally, a method was introduced for calculating the ice sheet thickness on the basis of air temperature alone. In this method, water temperature was calculated by using air temperature and simple equations, and a constant value was given to the effective water depth. The validity of the equations was confirmed through comparison of calculated values with the values obtained by continuous non-contact measurement of ice sheet thickness. The equations were used for retrospectively predicting the days when the river ice began to form and break up in each of the past nine years on an actual river.

\section{DEVELOPMENT OF SIMPLE EQUA- TIONS OF ICE SHEET THICKNESS}

An ice sheet thickness simulation model using heat flux was developed in a past study5). Accurate calculation of ice sheet thickness is possible with this model. The model, however, needs many different input values, including those of air temperature; water temperature; flow velocity; effective water depth; wind speed; latitude; cloud cover; combined density of the flowing water, frazil ice, ice sheets, and snow cover; latent heat; thermal conductivity; and heat exchange coefficient. The present study was conducted to reduce the number of necessary input values as well as to develop simple equations for ice sheet thickness. To make the model more practical, the only necessary input values are those of air temperature, water temperature, and effective water depth. Instead of using a smaller number of input values, the equations include the coefficients $\alpha$ and $\beta$, which relate to ice sheet formation and river ice melting, respectively. If it is possible to reduce the number of input values to one, namely, air temperature; the equations will become simpler and more versatile. In view of this, a method for calculating ice sheet thickness by using air temperature data alone was tested. In this method, air temperature data were used for calculating the water temperature, and a constant value was given to the effective water depth.

Actual river ice consists of cover snow, an ice sheet, and a frazil ice layer, which are simulated by an ice sheet thickness simulation model that uses heat flux. Field observations ${ }^{6}$ indicate that frazil ice becomes part of the ice sheet over time. Thus, to enhance the versatility of the equations, they were rearranged by taking into account frazil ice, as well as snow cover and ice sheets.

\section{(1) Derivation of basic equations}

Fig. 1 shows a conceptual diagram of heat balance in a frozen river. In Fig. 1, $T\left[{ }^{\circ} \mathrm{C}\right]$ is temperature; $h[\mathrm{~m}]$ is layer thickness; $\rho\left[\mathrm{kg} / \mathrm{m}^{3}\right]$ is the combined density of the flowing water, frazil ice, ice sheets, and snow cover; $U$ $[\mathrm{m} / \mathrm{s}]$ is flow velocity; and $\phi\left[\mathrm{W} / \mathrm{m}^{2}\right]$ is heat flux. Suffixes indicate the values of each layer. In addition, $L$ $[\mathrm{Ws} / \mathrm{kg}]$ is latent heat.

Changes in snow depth are expressed as

$$
\rho_{s} L_{s} \frac{d h_{s}}{d t}=\phi_{a}-\phi_{i u}
$$

Equation (1) takes into account the heat balance between the air and the ice sheets. 


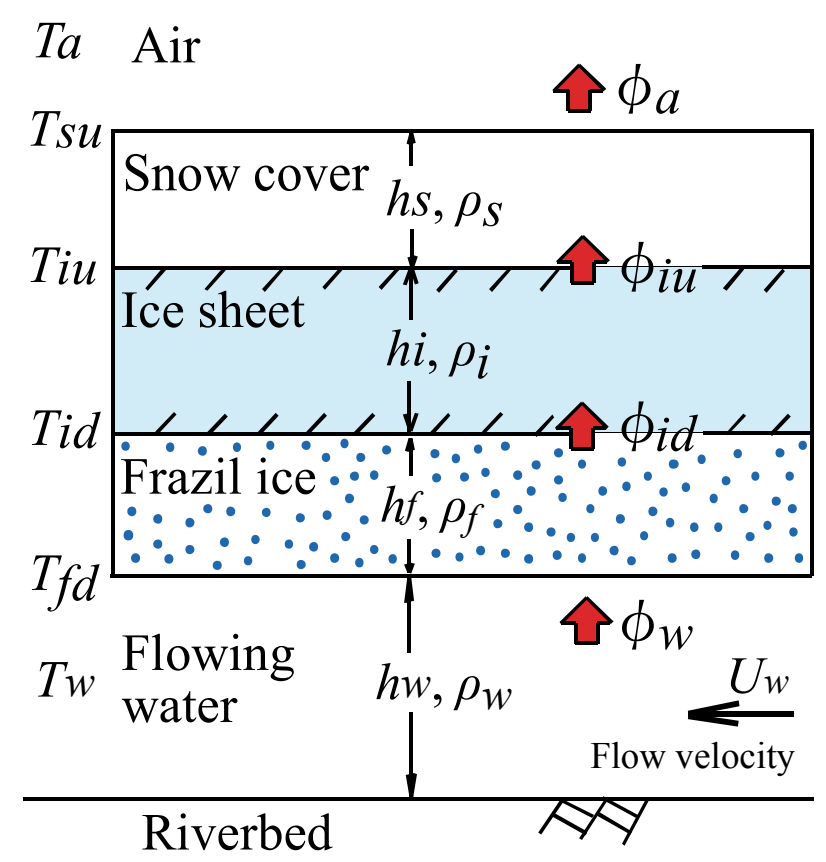

Fig. 1 Heat balance in a frozen river.

Changes in the ice sheet thickness are expressed as

$$
\rho_{i} L_{i} \frac{d h_{i}}{d t}=\phi_{i u}-\phi_{i d}
$$

Equation (2) takes into account the heat balance between snow cover and frazil ice.

Changes in the frazil ice thickness are expressed as

$$
\rho_{f} L_{f} \frac{d h_{f}}{d t}=\phi_{i d}-\phi_{w}
$$

Equation (3) takes into account the heat balance between ice sheets and flowing water.

Equations (1), (2) and (3) are rearranged into the following form:

$$
\rho_{i} L_{i} \frac{d h_{i}}{d t}=\phi_{a}-\rho_{s} L_{s} \frac{d h_{s}}{d t}-\rho_{f} L_{f} \frac{d h_{f}}{d t}-\phi_{w}
$$

(2) Heat flux $\phi_{a}$ from river ice surface to the air The heat flux in each layer is approximated as

$$
\begin{gathered}
\phi_{a}=h_{s a}\left(T_{s u}-T_{a}\right) \\
\phi_{\text {snow }}=\frac{k_{s}}{h_{s}}\left(T_{i u}-T_{s u}\right) \\
\phi_{i c e}=\frac{k_{i}}{h_{i}}\left(T_{i d}-T_{i u}\right) \\
\phi_{\text {frazil }}=\frac{k_{f}}{h_{f}}\left(T_{f d}-T_{i d}\right)
\end{gathered}
$$

These equations used the variables of heat exchange coefficient, thermal conductivity, ice layer thickness, and temperature difference, where $h_{s a}\left[\mathrm{~W} / \mathrm{m}^{2 \circ} \mathrm{C}\right]$ is heat exchange coefficient; $k_{s}\left[\mathrm{~W} / \mathrm{m}^{\circ} \mathrm{C}\right]$ is thermal conductivity of snow; and $k_{i}\left[\mathrm{~W} / \mathrm{m}^{\circ} \mathrm{C}\right]$ is thermal conductivity of ice sheet.

On the assumption that the change taking place at the interface of each layer at a given time is in equilibrium, $\phi_{a}=\phi_{\text {snow }}=\phi_{\text {ice }}=\phi_{\text {frazil }}$; thus, $\phi_{a}$ can be expressed as

$$
\phi_{a}=\frac{T_{f d}-T_{a}}{\frac{1}{h_{s a}}+\frac{h_{s}}{k_{s}}+\frac{h_{i}}{k_{i}}+\frac{h_{f}}{k_{f}}}
$$

\section{(3) Heat flux $\phi_{w}$ from flowing water to the bottom surface of river ice}

$\phi_{w}$ as calculated by the Equations below ${ }^{7)}$, reads

$$
\begin{aligned}
& \phi_{w}=h_{w i}\left(T_{w}-T_{i d}\right) \\
& h_{w i}=C_{w i} \frac{U_{w}^{0.8}}{h_{w}^{0.2}}
\end{aligned}
$$

Equation (11) uses water depth and flow velocity as independent variables, where $C_{w i}$ is $1622\left[\mathrm{~W} \mathrm{~s} \mathrm{~s}^{0.8} /{ }^{\circ} \mathrm{C}\right.$ $\mathrm{m}^{2.6}$ ], and $T_{i d}$ is the temperature of the bottom of ice sheets $\left(=0^{\circ} \mathrm{C}\right) \cdot U_{w}[\mathrm{~m} / \mathrm{s}]$ is the mean flow velocity, and $h_{w}[\mathrm{~m}]$ is the effective water depth from the riverbed to the bottom of the ice sheet.

When the values of $h_{w}$ are measured and the values of $U_{w}$ are not, an expression is derived for expressing the relation between $h_{w}$ and $U_{w}$, and then a measured value of $h_{w}$ is substituted into the equation in order to obtain the value of $U_{w}$. Manning's Equation is usually used for calculating the mean flow velocity in an iron or concrete pipe having a large cross-sectional area of flow. Although the conditions of a frozen river channel differ from those of a pipe, because the pressure of river water is relieved by cracks in the river ice, the river surface is almost entirely covered with ice; thus, it is possible to assume that the channel of a frozen river is similar to a pipe. For this reason, Manning's Equation is used as a relational equation regarding the mean flow velocity. The relation between the effective water depth $h_{w}$ and the mean flow velocity $U_{w}$ is expressed as

$$
U_{w}=\beta h_{w}{ }^{2 / 3}
$$


$\beta$ in Equation (12) is expressed as

$$
\beta=\frac{1}{2^{2 / 3}} \frac{\sqrt{i}}{n_{c}}
$$

where $n_{c}$ is Manning's roughness coefficient concerning combined roughness of riverbed and river ice, and $i$ is the hydraulic gradient.

When Equations (11) and (12) are substituted into Equation (10), $\phi_{w}$ can be expressed as

$$
\phi_{w}=C_{w i} \beta^{4 / 5} T_{w} h_{w}{ }^{1 / 3}
$$

\section{(4) Derivation of simple equations for ice sheet thickness}

When the finite difference method is applied to basic Equation (4) and when Equations (9) and (14) are substituted into it, then the equation of ice sheet thickness can be expressed as

$$
\begin{gathered}
h_{i}=h_{i}^{\prime}-A \frac{T_{a}}{h_{i}^{\prime}}-W T_{w} h_{w}{ }^{1 / 3} \\
A=\left(\frac{k_{i} \Delta t}{\rho_{i} L_{i}}\right) \alpha \\
W=\left(\frac{C_{w i} \Delta t}{\rho_{i} L_{i}}\right) \beta^{4 / 5}
\end{gathered}
$$

$0^{\circ} \mathrm{C}$ is given as the temperature on the bottom of the river ice $T_{f d}$. Then, coefficient $\alpha$ is defined as follows:

$$
\begin{aligned}
& \alpha=\alpha^{\prime} \times \alpha^{\prime \prime} \\
& \alpha^{\prime}=1-\frac{\rho_{s} L_{s} \frac{d h_{s}}{d t}}{\phi_{a}}-\frac{\rho_{f} L_{f} \frac{d h_{f}}{d t}}{\phi_{a}} \\
& \alpha^{\prime \prime}=\frac{\frac{h_{i}^{\prime}}{k_{i}}}{\frac{1}{h_{s a}}+\frac{h_{s}^{\prime}}{k_{s}}+\frac{h_{i}^{\prime}}{k_{i}}+\frac{h_{f}^{\prime}}{k_{f}}}
\end{aligned}
$$

When snow thickness and frazil ice thickness do not

\begin{tabular}{|c|c|c|c|c|c|}
\hline & $h_{s a}$ & $\rho_{i}$ & $L_{i}$ & $k_{i}$ & $\Delta t$ \\
\hline & $\begin{array}{c}\text { Heat } \\
\text { exchange } \\
\text { coefficient }\end{array}$ & Density & $\begin{array}{c}\text { Latent } \\
\text { heat }\end{array}$ & $\begin{array}{c}\text { Thermal } \\
\text { conduc- } \\
\text { tivity }\end{array}$ & Time \\
\hline 站 & $\frac{\mathrm{W}}{\mathrm{m}^{2{ }^{\circ} \mathrm{C}}}$ & $\frac{\mathrm{kg}}{\mathrm{m}^{3}}$ & $\frac{\mathrm{Ws}}{\mathrm{kg}}=\frac{\mathrm{J}}{\mathrm{kg}}$ & $\frac{\mathrm{W}}{\mathrm{m}^{2 \circ} \mathrm{C}}$ & $\mathrm{s}$ \\
\hline$\stackrel{\mathscr{\Xi}}{\frac{\mathscr{J}}{\pi}}$ & 25.0 & 917.4 & $\begin{array}{r}3.336 \\
\times 10^{5}\end{array}$ & 2.31 & 86400 \\
\hline
\end{tabular}
change with the passage of time, $\alpha^{\prime}$ is 1 . When snow thickness and frazil ice thickness become large, $\alpha^{\prime \prime}$ becomes small.

By substituting the values shown in Table 1 into Equation (15), a simple equation of ice sheet thickness can be expressed as
Table 1 Physical properties of ice.

$$
h_{i}=h_{i}^{\prime}-\left(\frac{65.2}{10^{5}}\right) \alpha \frac{T_{a}}{h^{\prime}{ }_{i}}-\left(\frac{45.8}{10^{2}}\right) \beta^{4 / 5} T_{w} h_{w}{ }^{1 / 3}
$$

Equation (17) is more practical and simpler than before. $\alpha$ [dimensionless] and $\beta\left[\mathrm{m}^{1 / 3} / \mathrm{s}\right]$ are used. This equation is explained below regarding an example in which the ice sheet thickness is calculated hourly. Because $T_{a}$ and $T_{w}$ in Equation (17) are daily mean values, when $T_{a}$ and $T_{w}$ are hourly values (i.e., 1 hour), input values are expressed by $T_{a} \times(1 / 24)$ and $T_{w} \times(1 / 24)$. The ice sheet thickness $h^{\prime}{ }_{i}$ is given an initial value of $1 \mathrm{~mm}$, and subsequently it is given a value 1 hour before the time of calculation.

When measured values are not available for $\alpha$, values of the ice sheet thickness measured in the past are used for determining the value of $\alpha$ by a trial and error method. The value of the coefficient $\beta$ is determined by using the existent observation data of flow rate and Equation (12). The ice sheet thickness $h_{i}[\mathrm{~m}]$ can be calculated hourly by using measured values of air temperature $T_{a}$, water temperature $T_{w}$, and effective water depth $h_{w}$.

The value of $\alpha^{\prime}$ [dimensionless] is greater when snow cover and frazil ice become part of the ice sheets, and the value of $\alpha^{\prime \prime}$ [dimensionless] is smaller when the snow depth and frazil ice thickness are large enough to be effective in insulating heat.

The effective water depth $h_{w}$ is expressed by Equation (18), which uses water level $H[\mathrm{~m}]$ and riverbed elevation $Z[\mathrm{~m}]$.

On the assumption that $h_{s}$ and $h_{f}$ are smaller than $h_{i}$, we have this approximation:

$$
\begin{gathered}
h_{w}=H-Z-\left(\frac{\rho_{s}}{\rho_{w}} h_{s}+\frac{\rho_{i}}{\rho_{w}} h_{i}+\frac{\rho_{f}}{\rho_{w}} h_{f}\right) \\
h_{w} \cong H-Z-0.917 h_{i}
\end{gathered}
$$

(5) Equation for calculating the ice sheet thickness by using air temperature alone

The three input values of air temperature, water temperature, and effective water depth are necessary 
for Equation (17). The equation will be much simpler and more versatile if a smaller number of input values suffice for calculation. For the purpose of reducing the number of input values, an equation is first derived for estimating the water temperature by using the air temperature. Then, a simple equation for calculating the ice sheet thickness is proposed. In this simple equation, the effective water depth is given as a constant value, and air temperature data are used as the only necessary input value.

The equation for the water temperature of a frozen river takes the following form:

$$
\frac{\partial\left(A \rho_{w} C_{p} T_{w}\right)}{\partial t}+(1-N) B h_{w a}\left(T_{w}-T_{a}\right)=0
$$

This is based on an equation that Yoshikawa et al.9) developed by improving a basic equation ${ }^{8}$. Equation (20) was rewritten by removing from the basic equation the terms for advection, diffusion, and heat flux from flowing water to the bottom of the river ice, where $T_{w}\left[{ }^{\circ} \mathrm{C}\right]$ : water temperature; $A\left[\mathrm{~m}^{2}\right]$ : cross-sectional area of flow $\left(\cong B h_{w}\right) ; \rho_{w}\left[\mathrm{~kg} / \mathrm{m}^{3}\right]$ : water density (given a value of 999.84 ); $C_{p}\left[\mathrm{~J} / \mathrm{kg}{ }^{\circ} \mathrm{C}\right]$ : specific heat of water (given a value of 4,200 ); $t$ [s]: time; $B[\mathrm{~m}]$ : river width; $h_{w a}\left[\mathrm{~W} / \mathrm{m}^{2}{ }^{\circ} \mathrm{C}\right]$ : heat exchange coefficient of water surface (given a value of 20); $N$ [dimensionless]: cross-sectional river-ice ratio (whose concept is shown in Fig. 2). $N$ is the ratio of river-ice width to river width $B(0 \leq \mathrm{N} \leq 1)$.

When the finite difference method is applied to Equation (20), the water temperature $T_{w}$ can be calculated as follows:

$$
\begin{aligned}
& T_{w}=\frac{T_{a}}{1+\gamma}+\frac{\gamma T_{w}^{\prime}}{1+\gamma} \\
& \gamma=\frac{h_{w} \rho_{w} C_{p}}{(1-N) h_{w a} \Delta t}
\end{aligned}
$$

In Equation (21), water temperatures below 0 are regarded as 0 in the calculations. When a river is not frozen, the water temperature is easily calculated by using air temperature data and substituting 0 for $N$ in Equation (22). $T^{\prime}{ }_{w}\left[{ }^{\circ} \mathrm{C}\right]$ in Equation (21) is the water temperature at the time $\Delta t$ before.

Fig. 3 shows water temperatures and air temperatures in terms of the values measured at Maruyama Gauging Station located $30 \mathrm{~km}$ from the mouth of the Teshio River, Hokkaido, together with the water temperatures calculated by using Equation (21). As a result of trial and error, the value of the coefficient $\alpha$ [dimensionless] was determined to be 0.6000 . On the

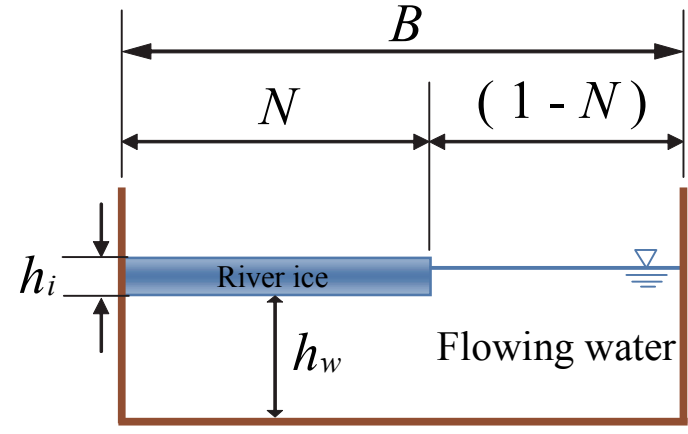

Riverbed

Fig. 2 The cross-sectional ice ratio in a frozen river.

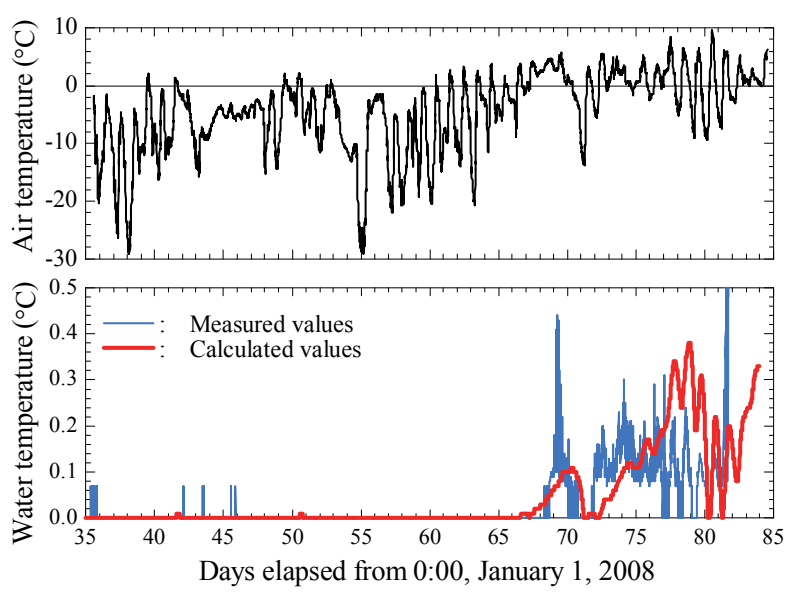

Fig. 3 Measured and calculated values of water temperature at Maruyama Gauging Station.

basis of the data on flow rates that had been collected when the river was frozen, 0.2381 was given as the coefficient $\beta\left[\mathrm{m}^{1 / 3} / \mathrm{s}\right]$. The effective water depth $h_{w}$ [m] was given a constant value of $2.24 \mathrm{~m}$, the average value of measurements. Regarding $N$, past observation results at the gauging station ${ }^{6}$ indicated that the thickness of the river ice correlated with the width of the river ice. After trial and error, this study assumes that the river is entirely frozen when the ice sheet thickness averaged for the transverse direction $h_{i}$ is $0.7 \mathrm{~m}\left(=h_{i \max }\right)$, and thus $N=1$. The ratio of the river ice width to the river width was calculated by using $N=$ $h_{i} / h_{\text {imax }}$.

In Fig. 3, the changes in the water temperature are expressed in increments of $0.01^{\circ} \mathrm{C}$, and the calculated values are consistent with the changes in the measured values as well as the days when the water temperature rose. However, on and after the 81 st day when the river ice had already begun to break up, the calculated values are not consistent with the measured values. The reason for this inconsistency is that the simple equation for calculating the water temperature does not take into account the effect of water flowing from the upper reaches of the river in raising the water temperature downstream. 


\section{APPLICABILITY OF THE SIMPLE EQUATION}

To verify the proposed model, calculated ice sheet thicknesses were compared with the values measured by using a continuous non-contact technique.

\section{(1) Continuous measurement of the ice sheet thickness}

The Teshio River in northern Hokkaido was used for the verification of the equations. Measurements were taken at Maruyama Gauging Station $30 \mathrm{~km}$ from the mouth of the river. The ice sheet thickness was observed for 49 days from 13:00 on February 5 through 13:00 on March 25, 2008, a period from when the river was covered with ice to when the ice breaks.

At $250 \mathrm{~m}$ upstream from Maruyama Gauging Station, the air temperature was measured every 10 minutes (with an MCS thermometer that has a measurement accuracy of JIS A class $\pm \leq 0.15^{\circ} \mathrm{C}$ ), and the flow discharge was observed 10 times in total. Additionally, time-series data on the water level were obtained from the MLIT database on hydrology and water quality.

At Maruyama Gauging Station, the ice sheet thickness was measured by using a continuous non-contact technique. The measuring technique is shown in Fig. 4. As shown in Fig. 4, the height of the snow cover surface and the height of the bottom of the ice sheet are measured hourly with a snow depth meter and an echosounder, respectively. The snow depth and the ice sheet thickness are estimated on the basis of the difference in the density of snow and ice. The snow depth is calculated using the equation $\left(h_{s}=\right.$ $\left.\left(d \rho_{w}-h_{s i} \rho_{i}\right) /\left(\rho_{s}-\rho_{i}\right)\right)$ with the measured thickness $h_{s i}\left(=h_{s}+h_{i}\right)$ between the snow cover surface height and ice sheet bottom height. This equation is held based on the Archimedes Principle. The draft $d$ is found from the water level and ice sheet bottom height. The density of the water $\rho_{w}$ is $999.84 \mathrm{~kg} / \mathrm{m}^{3}$. The density of the ice $\rho_{i}$ is $917.40 \mathrm{~kg} / \mathrm{m}^{3}$. The density of the snow $\rho_{s}$ is $100.00 \mathrm{~kg} / \mathrm{m}^{3}$. These densities are assumed to be constant in this paper. The snow depth meter (SDM-301S, Niigata Electronics Co.) has a measuring accuracy of $\pm 1.5 \mathrm{~cm}$ for depths of $\leq 3 \mathrm{~m}$, and of $\pm 2.5 \mathrm{~cm}$ for depths of $\geq 3 \mathrm{~m}$. The echosounder (PS-20R, $200 \mathrm{kHz}$, Kaijo Corp.) has a measuring accuracy of $\pm(3 \mathrm{~cm}+$ depth $\div 1000)$. In Fig. 4, the snow depth meter is set $60 \mathrm{~m}$ from the left bank at an elevation of $4 \mathrm{~m}$, and the echosounder is set on the riverbed $65 \mathrm{~m}$ from the left bank.

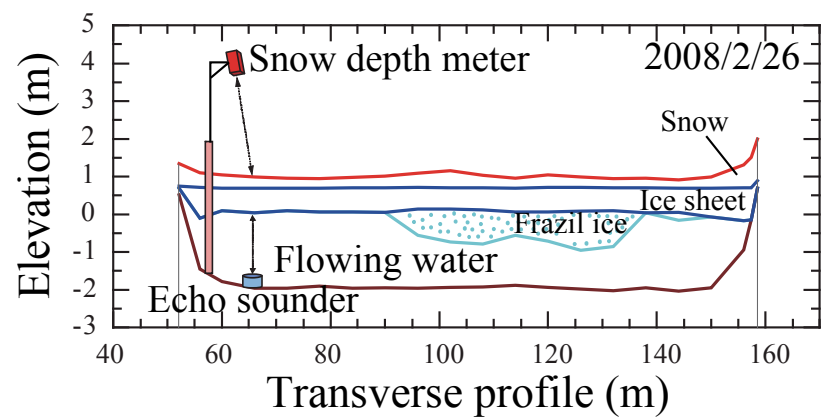

Fig. 4 Measuring instruments at Maruyama Gauging Station (30 km from the river mouth).

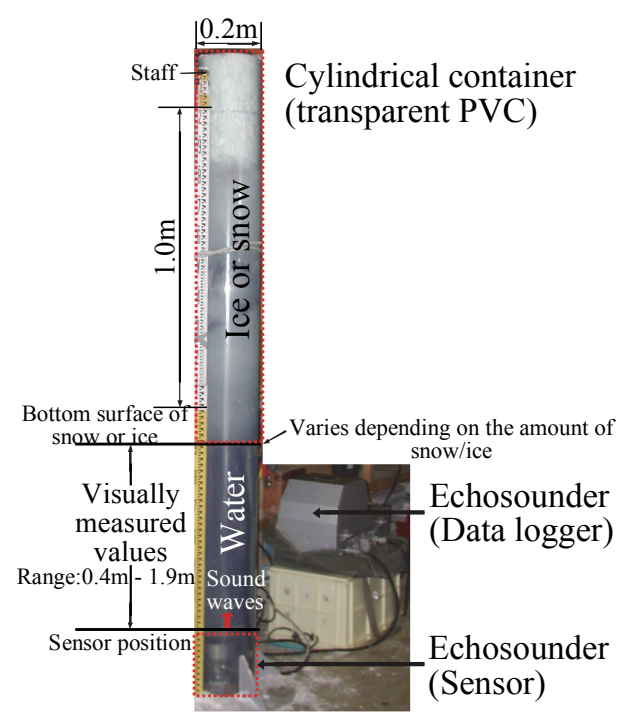

Photo 1 Test for measuring the height of the snow/ice bottom by using an echosounder.

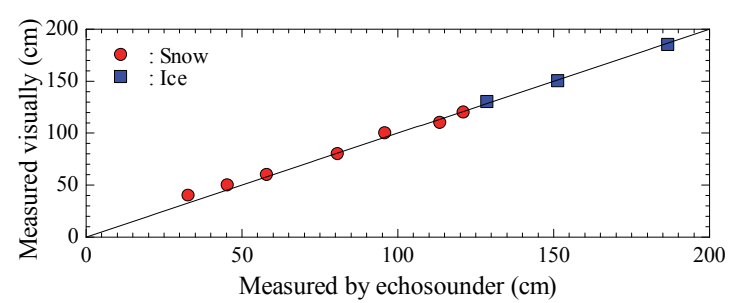

Fig. 5 Values measured by echosounder, and visually measured values.

(2) Accuracy in measuring the ice sheet thickness

Laboratory tests were conducted to determine whether an echosounder is useful for measuring the thickness of ice and snow. Photo 1 shows how the tests were conducted. A cylindrical container (transparent PVC) $0.2 \mathrm{~m}$ in diameter was filled with water. An echosounder was set at the bottom of the container. Snow or ice was put into the container from the top and was tamped down with a rod. The height of the bottom of the snow or ice was measured visually and with the echosounder. The distance between the sensor of the echosounder and the bottom of snow or ice varied from $0.4 \mathrm{~m}$ to $1.9 \mathrm{~m}$. Fig. 5 shows the values that were measured visually and with the echosounder. In Fig. 5, the measurement 
results show a stronger correlation for ice than for snow with respect to the relationship between the values measured with the echosounder and those measured visually. However, in terms of the whole data on ice and snow, the coefficient of correlation between the visually measured values and values measured with an echosounder is as high as 0.99 . Thus, it can be concluded that an echosounder accurately measures the height of snow and ice.

\section{(3) Comparison of measured and calculated values of ice sheet thickness}

Fig. 6 shows the ice sheet thickness in terms of continuously measured values, visually measured values, and calculated values. Three types of calculated values are shown in Fig. 6. Two of them were calculated by the simple equations proposed in this study, using air temperature, water temperature, and effective water depth as input values, or air temperature alone as an input value. The other was calculated by using Stefan's Equation for calculating the ice sheet thickness.

The relationship between Stefan's Equation and the simple equations is described as follows. Stefan's Equation takes the following form:

$$
\hat{h}_{i}=\hat{\alpha} \sqrt{S}
$$

Stefan's Equation is derived in the form of Equation (23) after assigning 0 to $\phi_{w}$ in Equation (4), separating the variables and integrating Equation (4) with respect to time; where $\hat{h}_{i}[\mathrm{~m}]$ is the ice sheet thickness and $S$ [ $\left.{ }^{\circ} \mathrm{Cday}\right]$ is the freezing index. The freezing index is the cumulative number of degree-days with daily mean temperature below zero, counted from the day the calculation starts.

The relationship between $\hat{a}$ in Stefan's Equation (23) and $\alpha$ in the simple Equation (17) is expressed as

$$
\hat{\alpha}=\sqrt{\alpha \times \frac{2 k_{i} \Delta t}{\rho_{i} L_{i}}}, \quad \alpha=\frac{\hat{\alpha}^{2}}{0.0013}
$$

The values in Table 1 were input into the equation. When $\alpha=0.6000$, then $\hat{a}$ is 0.0279 . In Fig. 6, the values calculated by Stefan's Equation and those calculated by the simple equations are more or less the same and are consistent with the measured values for the time when ice sheets begin to form. Regarding the period from when the river ice begins to melt to when it has completely melted, because Stefan's Equation does not take into account the melting of ice, as the form of the equation shows, the calculated values are not consistent with the measured values. In contrast, the simple equations take into account

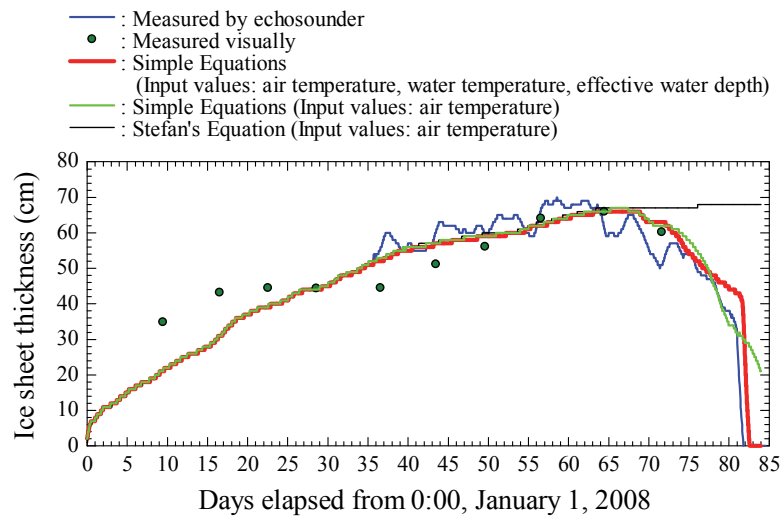

Fig. 6 Comparison of ice sheet thickness at Maruyama Gauging Station.

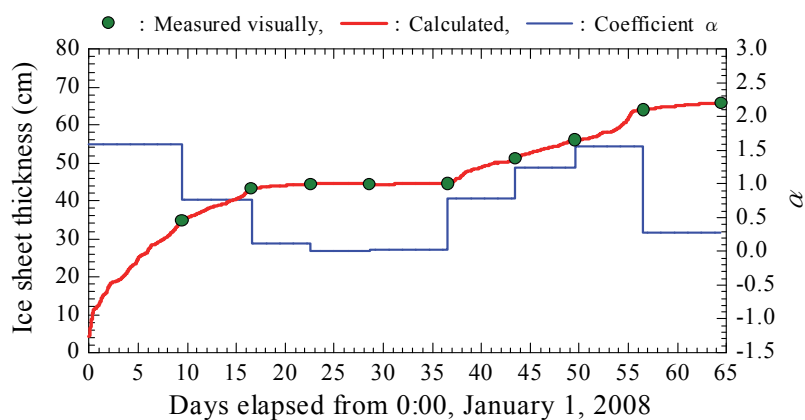

Fig. 7 Ice sheet thickness at Maruyama Gauging Station (visually measured and calculated) and the coefficient $\alpha$.

the melting of ice sheets; thus, the calculated values accurately reproduce the measured values.

The values calculated by using the simple equations using air temperature, water temperature, and effective water depth as input values accurately reproduced the variations in the measured values. This result suggests that the changes in the ice sheet thickness can be simulated by using appropriately determined values of coefficients $\alpha$ and $\beta$ and known values of air temperature, water temperature, and effective water depth. Complicated calculations of heat flux are not necessary. Regarding the estimation of the day when the river ice begins to break up, however, the calculated values lag behind the measured values and predict that ice breaking takes place later than it actually does. It is possible that the lag was caused by the fact that the simple equations do not take into account the effect of river ice that flows downstream. The lag time is about 19 hours.

Although the values calculated by the simple equation using the air temperature alone as an input value do not accurately estimate the day when river ice begins to break up, these values are consistent with the changes in the ice sheet thickness from the time when river ice begins to form to the time when the ice begins to break up. It should be noted that calculation results depend on the value of $h_{i \max }$ used for calculating the ratio of the river-ice width to the 
Table 2 Coefficient $\alpha$ : Correlation with each of $F, a$ and $b$ (49 observatories, 249 data points).

\begin{tabular}{|c|c|c|c|c|c|c|}
\hline$F$ & $I_{b}$ & $I_{w}$ & $B / h_{w}$ & $I_{b} B / h_{w}$ & $I_{w} B / h_{w}$ & $F_{r}$ \\
\hline Coefficient of correlation & 0.05 & 0.08 & 0.71 & 0.19 & 0.01 & 0.23 \\
\hline$a$ & -1162.791 & -1162.791 & -0.029 & -2.770 & -91.743 & -6.993 \\
\hline$b$ & 3.488 & 1.988 & 3.768 & 0.906 & 18.200 & 1.713 \\
\hline
\end{tabular}

Table 3 Coefficient $\beta$ : Correlation with each of $F, a$ and $b$ (49 observatories, 249 data points).

\begin{tabular}{|c|c|c|c|c|c|c|}
\hline$F$ & $I_{b}$ & $I_{w}$ & $B / h_{w}$ & $I_{b} B / h_{w}$ & $I_{w} B / h_{w}$ & $F_{r}$ \\
\hline Coefficient of correlation & 0.31 & 0.56 & 0.34 & 0.46 & 0.64 & 0.99 \\
\hline$a$ & 480.769 & 438.593 & 0.016 & 2.445 & 2.700 & 4.237 \\
\hline$b$ & -0.538 & 0.154 & -1.100 & 0.083 & 0.306 & -0.097 \\
\hline
\end{tabular}

river width $N$, and that when $h_{i \max }$ is given the value of 0.75 , the calculation results accurately predict the day of ice breaking. Further study is needed regarding an appropriate value for $h_{i \max }$, but the equations are very simple in a physical sense, and they are likely to produce calculation results that can predict the changes in the thickness of an ice sheet from its formation to melting by using a sole input value (i.e., the air temperature).

However, values calculated by the simple equations were not consistent with the visually measured values of the ice sheet thickness. One of the reasons for this could be that the coefficient $\alpha$ was given a constant value. Thus, variations in the values of the coefficient $\alpha$ were identified on the basis of the visually measured values of the ice sheet thickness. Fig. 7 shows the values of $\alpha$ that were calculated such as to be consistent with the visually measured values. The value of $\alpha$ changes as shown in Fig. 7. This result affirms that the values calculated by the simple equations are inconsistent with the continuously or visually measured values, due to the fact that a constant value is given to the coefficient $\alpha$.

\section{(4) Study on the values of $\alpha$ and $\beta$}

The comparison between the measured values and the calculated values of the ice sheet thickness showed that the simple equations proposed in this study are useful for calculating the ice sheet thickness when the values of $\alpha$ and $\beta$ are appropriately determined. To identify the appropriate values of these coefficients, their relationships with the hydraulic quantity and basic characteristics of the river channel, such as bed slope, river width, and water depth were studied.

The period for study was December 2005 through March 2006. Of the 13 river systems in Hokkaido, 12 systems, excluding the Shiribeshitoshibetsu River, were chosen for the study, as these satisfied the conditions of the river freezing in winter and the bed slope gradient being known. The total number of observatories was 49. The study used 249 data points, which were collected at these observatories until each ice sheet grew to the maximum thickness.

Regarding $\alpha$, the difference between a measured and a calculated value for ice sheet thickness was determined by changing the value of $\alpha$ in increments of 0.001 in the range from 0.001 to 3.000 , and the value that resulted in the minimum difference was determined to be the value of $\alpha$. The mean cross-sectional ice sheet thickness used in calculations was obtained by dividing the cross-sectional area of an ice sheet by the river width based on the results of cross-sectional surveying. The value of $\beta$ was calculated by using Equation (12) and data on flow rates. The effective water depth hw was calculated by using $h_{w}=A / B\left(A\left[\mathrm{~m}^{2}\right]=\right.$ an area of flowing water; and $B[\mathrm{~m}]=$ the width of water surface). The relation of $\alpha$ or $\beta$ to each of the values ( $F$ ), such as the mean bed slope $I_{b}$, the mean water surface slope $I_{w}$, the river width/depth ratio $B / h_{w}$, and the Froude number $F_{r}$ was expressed by linear equations taking the following form:

$$
\begin{aligned}
& \alpha=a F+b \\
& \beta=a F+b
\end{aligned}
$$

$F$ is a general term for these values. In these equations, the value of the mean bed slope $I_{b}$, the mean water surface slope $I_{w}$, the river width/depth ratio $B / h_{w}$, or the Froude number $F_{r}$ is substituted for $F . a$ and $b$ are coefficients. The coefficients of correlation between $\alpha$ and $F$ and between $\beta$ and $F$ are shown in Table 2 and Table 3, respectively. Regarding the coefficient $\alpha$, the correlation with $F$ is, in order from high to low, $B / h_{w}, F_{r}$, and $I_{b} B / h_{w}$. Regarding the coefficient $\beta$, the correlation with $F$ is, in order from high to low, $F_{r}, I_{w} B / h_{w}$, and $I_{w}$.

The coefficient $\alpha$ expresses the extent of ice sheet 
formation relative to the air temperature. The greater $\alpha$ becomes, the greater the ice sheet grows. In a physical sense, the value of $\alpha$ becomes larger when snow and frazil ice become part of the ice sheet, and the value becomes smaller when snow cover and frazil ice are effective in insulating heat. The coefficient $\beta$ expresses the extent of ice sheet melting relative to the water temperature and the effective water depth. The greater $\beta$ becomes, the more the ice sheet melts. In a physical sense, the value of $\beta$ becomes larger when the hydraulic gradient is large and the roughness is small, and the value becomes smaller when the hydraulic gradient is small and the roughness is large.

\section{METHOD FOR PREDICTION OF ICE FORMATION AND ICE BREAKUP}

The days when ice began to form and the days when ice broke up in the past nine years on an actual river were retrospectively predicted by using the simple equations proposed in this study and time-series data on the air temperature.

\section{(1) Calculation conditions}

By using the simple equations, the days when ice began to form and the days when ice broke up were retrospectively predicted for the period from November 2002 through March 2011. The data used for verification were collected at Onnenai Gauging Station, $111.8 \mathrm{~km}$ upstream from the mouth of the Teshio River, Hokkaido. The values of $\alpha$ and $\beta$ in Equation (17) were obtained by the following equations:

$$
\begin{gathered}
\alpha=0.906-2.770 \frac{I_{b} B}{h_{w}} \\
\beta=\frac{U_{w}}{h_{w}{ }^{2 / 3}} \\
U_{w}=\frac{Q}{B h_{w}} \\
h_{w}=\left(\frac{n_{c} Q}{B \sqrt{I_{b}}}\right)^{3 / 5}
\end{gathered}
$$

The flow rate $Q\left[\mathrm{~m}^{3} / \mathrm{s}\right]$ is a mean low flow rate calculated by using the flow rate data collected at Onnenai Gauging Station. In order from 2002 to 2011, the mean low flow rates were 49.27, 51.87, 55.66, $54.01,52.70,46.75,64.93,71.71$, and 64.83. The river width $B[\mathrm{~m}]$ was $96 \mathrm{~m}$, the riverbed slope $I_{b}$ [dimensionless] was $1 / 1386$ (according to the periodic cross-section survey in fiscal 2007), and the roughness coefficient $n_{c}$ was 0.03 . These values were the same for all nine years. The water temperature was calculated by using Equation (21). The measured values of river ice thickness obtained in the past flow rate observation were used for trial and error, and the value of $N$ was determined to be 0.99 on the assumption that the river was entirely frozen when the mean transverse ice sheet thickness $h_{i}$ was $0.8 \mathrm{~m}$ $\left(=h_{i \max }\right)$. In the calculations done using the simple equations, hourly data on the air temperature collected at Otoineppu Gauging Station $15.3 \mathrm{~km}$ from Onnenai Gauging Station were used.

\section{(2) Prediction of the days when ice began to form and began to break up}

Fig. 8 shows measured water levels and calculated values of ice sheet thickness for the nine years from November 2002 through March 2011 at Onnenai Gauging Station. Because no observation data were available regarding the ice formation period and the ice breakup period, these two periods were defined as and were used as part of the measurement data as follows: The ice formation period is the period from when the water level begins to rise to when it reaches its maximum. The ice breakup period is the period from when the water level begins to fall to when it reaches the level before the ice began to form. In Fig. $\mathbf{8}$, these periods are shown in green.

Fig. 8 shows that the water level suddenly rises when the ice sheet thickness reaches a certain value, and that the water level falls when the ice sheet thickness decreases. According to the calculated values of the ice sheet thickness, the mean ice sheet thickness $[\mathrm{m}]$ in the ice formation period in each of the nine years is between 0.15 and 0.33 , and the average value for the nine years is $0.23 \mathrm{~m}$. River ice begins to break up the ice sheet thickness as its maximum begins to decrease. The beginning of the ice-forming period seems to be greatly affected by the amount of snow that is directly supplied from the snow cover into the river channel. The average snow depth $[\mathrm{cm}]$ in the ice formation period in each year is shown in Fig. 9. The average snow depth is between $40 \mathrm{~cm}$ and $160 \mathrm{~cm}$, and the average for the nine years is $108 \mathrm{~cm}$.

On the basis of the data shown above, the beginning of the ice formation period was defined as the day when the calculated value of the ice sheet thickness is $0.2 \mathrm{~m}$ or greater and when the snow depth has reached $0.1 \mathrm{~m}$ or greater. The beginning of the ice breakup period was defined as the day when the calculated thickness of the ice sheet becomes 0.1 

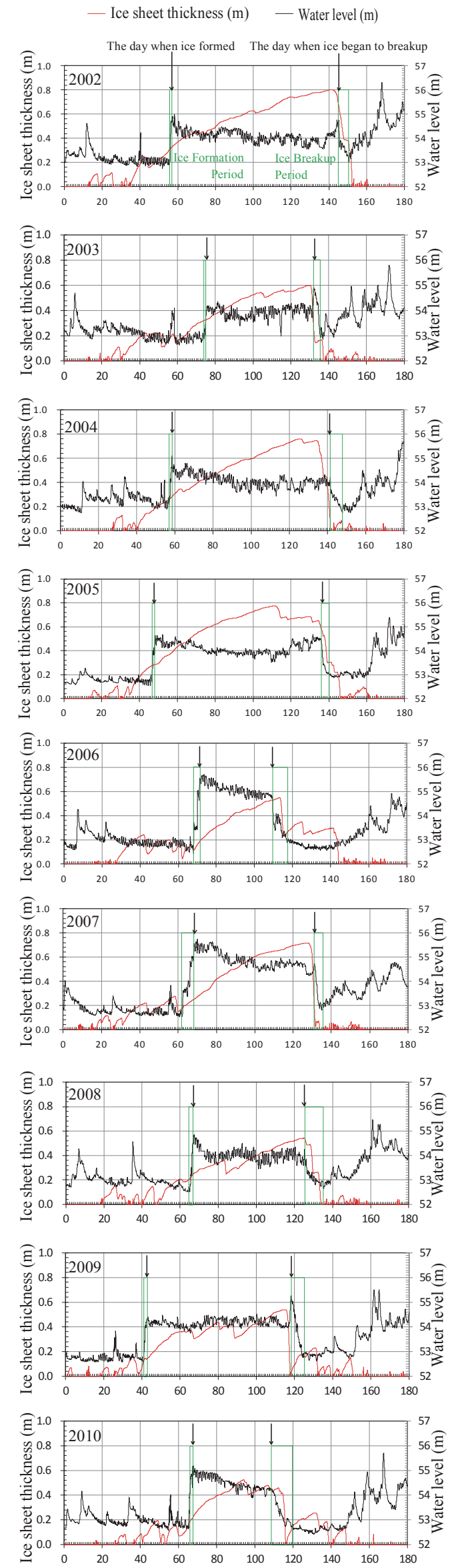

Fig. 8 Measured water levels and calculated values of ice sheet thickness.

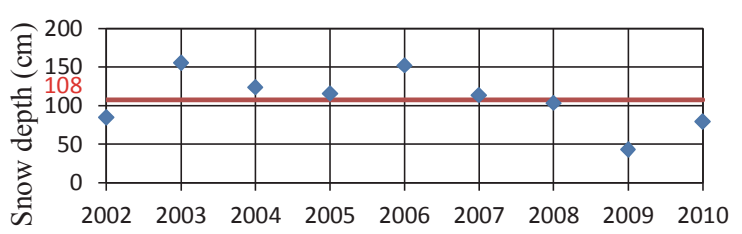

Fig. 9 Snow depth in the ice formation period (Otoineppu Gauging Station).

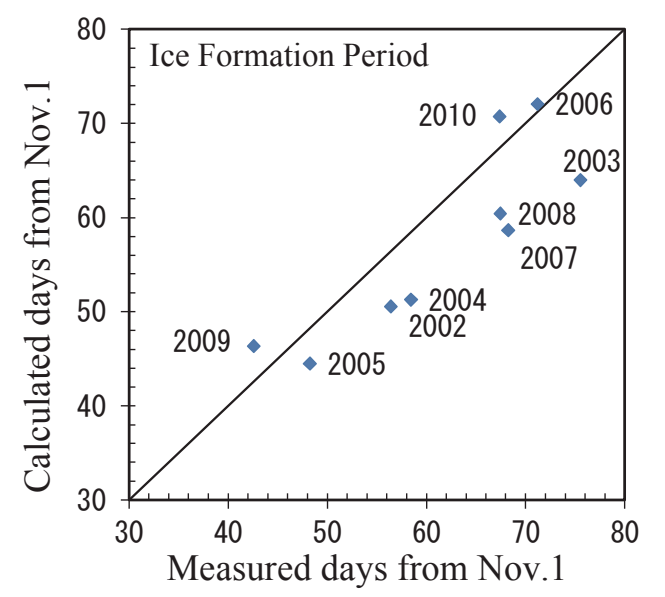

a) Ice Formation Period

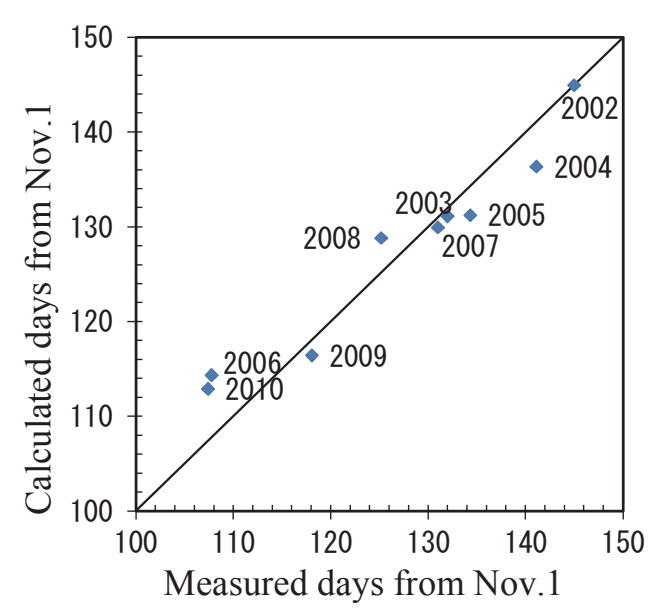

b) Ice Breakup Period

Fig. 10 Prediction of the ice formation periods and the ice breakup periods on measured values and calculated values.

$\mathrm{m}$ less than the calculated maximum thickness. On the basis of the above-mentioned definitions as determined by water levels, Fig. 10 shows the prediction of the ice formation periods and the ice breakup periods according to the measured values and calculated values. Measured values are the day when ice formed and the day when ice began to break up in Fig. 8.

In Fig. 10, The mean absolute errors in the prediction of the day when ice began to form and the day when ice began to break up on the basis of the calculated values were 6 days and 2 days, respectively, 
in comparison with the predictions based on the measured values. In five years, the error was 6 days or fewer in the prediction of the ice formation period. In four years, the error was 2 days or fewer in the prediction of the ice breakup period. Thus, both periods were accurately predicted by using the calculated values. One of the reasons for the relatively large values of absolute error in the prediction of ice formation periods seems to be the fact that the effects of ice flowing down from the upper reach and accumulating downstream are not taken into account.

\section{CONCLUSION}

A simple and practical model for calculating the ice sheet thickness was developed on the basis of an ice sheet thickness simulation model using heat flux. The calculation model used air temperature, water temperature, and effective water depth as independent variables. The simple equations proposed in this study are inapplicable under certain conditions. For example, it is not possible to assign a constant value to the coefficient $\alpha$ when any of the following is dominant: increase of snow cover due to snowfall, change in the volume of snow cover due to wind, or increase/decrease of frazil ice due to flowing water. Similarly, the coefficient $\beta$ cannot be given a constant value when the bottom of the river ice has large geometric variations. Nevertheless, the comparison between the measured values and the values calculated by the equations indicate that the equations can be used for accurately predicting the period from when ice sheets begin to form to when they begin to break up, if the values of these two coefficients are appropriately determined.

In developing equations for calculating the ice sheet thickness, simple equations for estimating the water temperature by using the air temperature were adopted. A constant value was assigned to the effective water depth. As a result, a method was proposed for calculating the ice sheet thickness by using a sole input value: the air temperature. It was proved that the values calculated by this method are consistent with the variations in the measured values.

A continuous non-contact method was also introduced for measuring the height of both the snow cover surface and the bottom of the ice with a snow depth meter and an echosounder. Laboratory test results showed that the echosounder accurately measured the height of the snow cover surface and the bottom of the ice. It was also shown that the measurement results had a stronger correlation for ice than for snow with respect to the relationship between the values measured with the echosounder and those measured visually.

The ice formation periods and the ice breakup periods in the past nine years on an actual river were retrospectively predicted by using the simple equation that took air temperature as the sole input value. The mean absolute errors in the prediction of the day when ice began to form and the day when ice began to break up on the basis of the calculated values were 6 days and 2 days, respectively, in comparison with the predictions based on the measured values. Thus, both periods were accurately predicted by using the calculated values.

ACKNOWLEDGMENTS: This work was supported by JSPS KAKENHI Grant-in-Aid for Young Scientists (B) 26870023 and JSPS Kakenhi Grant-in-Aid for Scientific Research (B) 24360197. The Hokkaido Regional Development Bureau provided the observational data that were essential to conduct this research. Fukuda Hydrologic Center Co., Ltd. assisted us in conducting field observations. Their assistance and support are greatly appreciated.

\section{REFERENCES}

1) Shen, H. T.: Mathematical modeling of river ice processes, Cold Regions Science and Technology, Vol.62, pp.3-13, 2010.

2) Yoshikawa, Y., Watanabe, Y., Hayakawa, H. and Hirai, Y.: Development of a Discharge Estimation Method for Frozen Rivers, Journal of Hydroscience and Hydraulic Engineering, Vol.29, No.1, pp.81-105, 2011.

3) Shen, H. T. and Liu, L.: Shokotsu River ice jam formation, Cold Regions Science and Technology, Vol.37, pp.35-49, 2003.

4) Yoshikawa, Y., Watanabe, Y., Hayakawa, H. and Hirai, Y.: Field Observation of a River Ice Jam in the Shokotsu River in February 2010, Proceedings of the 21th IAHR International Symposium on Ice, pp.105-117, 2012.

5) Shen, H. T. and Chiang, L. A.: Simulation of Growth and Decay of River Ice Cover, Journal of Hydraulic Engineering, Vol.110, No.7, pp.958-971, 1984.

6) Yoshikawa, Y. and Watanabe, Y.: Frazil Increase and Ice Thickness Formation of Frozen Rivers, Proceedings of the 19th IAHR International Symposium on Ice, pp.51-61, 2008.

7) Ashton, G. D. Ed.: River Lake Ice Engineering, Water Resources Publications, pp.233-236, p.289, 1986.

8) Wasantha Lal, A. M. and Hung, T. S.: Mathematical Model for River Ice Processes, Journal of Hydraulic Engineering, Vol.117, No.7, pp.851-867, 1991.

9) Yoshikawa, Y., Watanabe, Y., Hayakawa, H. and Hirai, Y.: Study on One-dimensional Calculation of the Water Temperature in a Frozen River, The 65th Annual Meeting, Japan Society of Civil Engineers, pp.409-410, 2010.

(Received December 27, 2013) 